\title{
Are changes in atmospheric cleansing responsible for observed variations of impurity concentrations in ice cores?
}

\author{
Margareta E. Hansson \\ Stockholms Meteorologiska institutionen universitet, S-106 91 Stockholm, Sweden
}

\begin{abstract}
A simple model tests the effect on ice-core impurity concentrations of climate-induced changes in the physical conditions of the atmosphere influencing transport and deposition processes, while keeping source areas and production rates constant. The model results show that the increased glacial concentrations observed for most impurities can be explained entirely by changes in transport and deposition. No increase in source emission is necessary, however possible, to explain the ten-fold increase in impurity concentrations during the Last Glacial Maximum. This shows that the effect of dynamic changes in the atmosphere can be large and has to be taken into account before translating deposition records into emission records. The total impurity content in the global atmosphere during the glacial period was higher if dynamic changes in the atmosphere rather than source-emission changes were responsible for the variations observed in polar areas. This implies that a climateforcing mechanism is to be found in the dynamics of the atmosphere, since the radiative properties of the atmosphere depend on the total content of impurities in the atmosphere. The effect on the climate can probably be compared with, although opposite in sign to, the present-day anthropogenic greenhouse forcing.
\end{abstract}

\section{INTRODUCTION}

Records from polar ice sheets contain invaluable information about past variations in the climate and the composition of the atmosphere. Past temperatures and precipitation rates are deduced from stable water-isotope records, and past concentrations of greenhouse gases are revealed from air bubbles captured in the ice. Soluble (ion) and insoluble (dust) compounds forming the atmospheric aerosol are scavenged by the precipitation from the air mass above the ice sheet, or dry-deposited on the ice-sheet surface, and become incorporated in the ice. Concentration records of ions and dust from ice cores can reveal the past atmospheric-aerosol composition and concentration. Air-snow transfer functions are at present poorly known, but considerable effort has recently been put into this field of research (e.g. Dibb and others, 1992; Jaffrezo and Davidson, 1993). However, the atmospheric aerosol has a high spatial variability due to the short residence times in the atmosphere of most compounds forming the aerosol. This complicates any attempt to extrapolate such information from polar ice cores to a global scale.

The airborne concentration of any impurity in the air mass above the ice sheet is dependent on the strength and location of the source, the atmospheric residence time of the impurity and the transit time of the air parcel from the source area to the deposition site. The pattern of general circulation of the atmo- sphere determines which source areas influence the deposition site. Impurity concentration in the ice is dependent on the airborne concentration and the local total scavenging (by wet and dry deposition). All these parameters can change with a change in climate. If icecore impurity concentrations representing such different climatic conditions as glacials and interglacials are compared, possible changes in all these parameters have to be taken into account. Changes in deposition records cannot be directly translated into changes in emissions.

Increased ice-core impurity concentrations in glacial stages have often been attributed to expanded source areas and increased production rates, but this hypothesis has not been verified. General circulation models fail to reproduce expanded source areas and increased production rates for dust that could account for the observed increases (Joussaume, 1993). The residence time of an impurity in the atmosphere is determined by wet and dry deposition and chemical transformation processes along the transport path to the deposition site. The residence time is probably longer in a glacial atmosphere as an effect of a lower water-vapour capacity in a colder atmosphere and, hence, a lower wet scavenging rate of the impurity. The transit time of an air parcel is probably shorter in a glacial atmosphere because of higher mean wind speeds, provided that the distance to the influencing source area is identical. A change in the pattern of the general circulation 
(Anderson and others, 1988; Joussaume, 1993) may alter the effective distance to the source area or make other source areas influence a specific receptor area. Both increased residence times and decreased transit times will enhance the airborne concentrations in the remote polar areas.

Any change in source strength and location will affect the impurity concentration individually for each impurity, while changes in the physical conditions of the atmosphere can be expected to influence all impurities systematically. Taking advantage of recent multi-ion ice-core analyses, where many different sources and source types are represented, may reveal systematic changes of ice-core impurity concentrations with large changes in the climate. Similar problems have recently been addressed in the GISP2 ice core (Mayewski and others, 1993) but the approach was different and the study restricted to the Younger Dryas event. The high time resolution (a few years per sample) in that study revealed rapid changes (within a decade or less) in atmospheric composition.

In this study, a simple model is formulated to test the effects of changes in residence times and transit times (two parameters which can respond quickly to climatic changes) while keeping source areas and production rates constant. The continuous concentration profiles of dust and nine ions $\mathrm{CH}_{3} \mathrm{SO}_{3}, \mathrm{Cl}, \mathrm{NO}_{3}{ }^{-}, \mathrm{SO}_{4}{ }^{2-}, \mathrm{Na}^{+}, \mathrm{NH}_{4}{ }^{+}$, $\left.\mathrm{K}^{+}, \mathrm{Mg}^{2+}, \mathrm{Ca}^{2+}\right)$, in the period $10000-120000 \mathrm{BP}$ and in the 19th century, from the Renland ice core, East Greenland (Hansson, 1994), are used in this test.

\section{THE RENLAND ICE CORE}

The $324 \mathrm{~m}$ long surface-to-bedrock Renland ice core was recovered from the summit of the small separate Renland ice cap $\left(71^{\circ} 18^{\prime} \mathrm{N}, 26^{\circ} 43^{\prime} \mathrm{W}\right)$ during the Nordic Renland Project in 1988 (Johnsen and others, 1992a). The Renland ice cap covers the entire high-elevation plateau (summit elevation $2340 \mathrm{~m}$ a.s.l.) of the Renland peninsula at the bottom of the Scoresbysund fjord. The present mean annual temperature is $-18^{\circ} \mathrm{C}$ and the mean annual accumulation is $50 \mathrm{~cm}$ ice equivalent. The Renland ice core covers a full glacial cycle back to approximately $130000 \mathrm{BP}$. The entire record of the last glacial period and the previous interglacial Eemian is compressed into the deepest $20 \mathrm{~m}$ but well preserved despite the closeness to the bedrock. This is confirmed by the similarity all the way back to the Eemian between the stable oxygenisotope $\left(\delta^{18} \mathrm{O}\right)$ record from the Renland ice core and the new records from the less compressed ice cores (GRIP and GISP2) from Summit, Greenland (Dansgaard and others, 1993; Grootes and others, 1993). Also the irregular glacial interstadials with a duration of 500-2000 years are clearly identified in the Renland $\delta^{18} \mathrm{O}$ record (Johnsen and others, 1992b). The only exception is the presence of a $4 \mathrm{~m}$ thick layer in the Renland ice core, $5-9 \mathrm{~m}$ above bedrock, with very low constant $\delta^{18} \mathrm{O}$ values and a very high constant impurity content. This section has no counterpart in any other climatic record; it may originate from random thinning of layers of different rigidity (the boudinage effect (Staffelbach and others, 1988)).

The $\delta^{18} \mathrm{O}$ record presented on the calculated time- scale (Fig. 1), with the homogeneous layer compressed to represent only 1000 years of snow accumulation at $64000 \mathrm{BP}$, is fully consistent with other climatic records. The concentration profile of calcium is shown in Figure 1. The Renland calcium profile is fully consistent with the calcium profile from the GRIP ice core from Summit (GRIP Members, 1993), in terms both of variations and of absolute concentrations. This indicates that both ice cores are representative of a larger region and that the strong increase at Renland of crustal impurities in glacial stages is not due to a local coastal source.

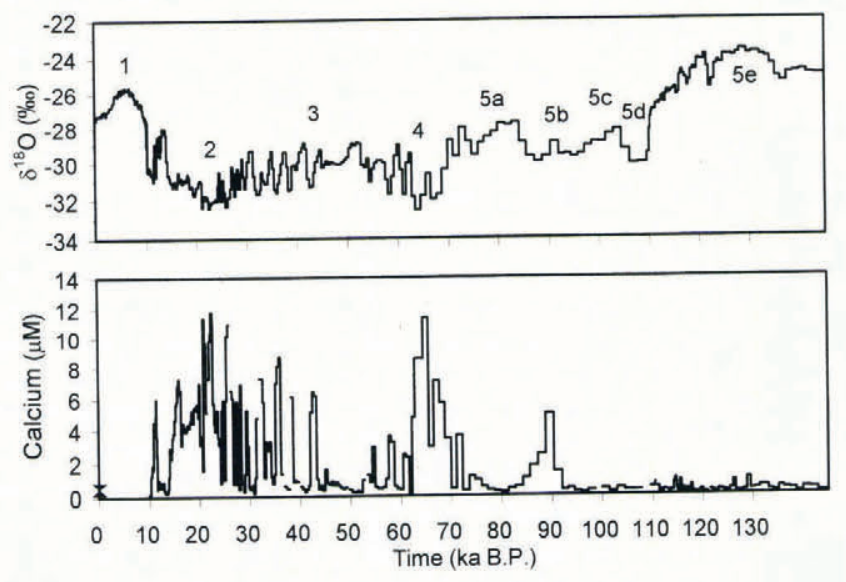

Fig. 1. Top: the Renland ice-core $\delta^{18} O$ profile on a calculated time-scale; the marine isotope stages are indicated. Bottom: the Renland ice-core calcium profile; the 19th-century mean value is indicated by a cross to the left.

\section{MODEL DESCRIPTION}

The loss of any impurity with an airborne concentration $C_{\text {air }}\left(M / L^{3}\right)$ may be described as a first-order process defined by the scavenging rate $\Psi(1 / T)$ :

$$
\mathrm{d} C_{\text {air }} / \mathrm{d} t=-\Psi C_{\text {air }} .
$$

By solving Equation (1), the change in airborne concentration with time can be described by

$$
C_{\text {air }}=C(0)_{\text {air }} \exp (-\Psi t)
$$

if $\Psi$ is constant. $C_{\text {air }}$ is the airborne concentration in the moving air parcel and $C(0)_{\text {air }}$ is the airborne concentration at the source. The average residence time $\tau$ is defined by $\tau=1 / \Psi$, thus giving the expression:

$$
C_{\text {air }}=C(0)_{\text {air }} \exp (-t / \tau) \text {. }
$$

Without knowing the absolute airborne concentration, the concentration relative to a reference state (denoted by an asterisk) can be calculated from

$$
C_{\text {air }} / C_{\text {air }}^{*}=C(0)_{\text {air }} / C(0)_{\text {air }}^{*} \exp \left[(1-n / k) t^{*} / \tau^{*}\right]
$$


where $\left(C(0)_{\text {air }} / C(0)_{\text {air }}^{*}\right)$ is the relative airborne concentration at the source and thus reflects changes in source strength, $n$ is the relative transit time $\left(t / t^{*}\right)$, and $k$ is the relative residence time $\left(\tau / \tau^{*}\right)$.

The concentration in the ice $C_{\text {ice }}(M / M)$ and the total deposition flux $\Phi_{\text {tot }}\left(M / L^{2} T\right)$, derived from $C_{\text {ice }}$ and the local precipitation rate $P(L / T)$, are quantities which can be measured in ice cores and can tell us about airborne concentrations in the past. Wet scavenging is the dominant deposition process for the atmospheric aerosol in areas with high precipitation rates (e.g. Greenland under interglacial climate conditions and coastal areas of Antarctica), while dry deposition dominates in areas with very low precipitation rates (e.g. the interior of Antarctica). If dry deposition is negligible, changes in concentration in the ice can be approximately related to changes in airborne concentration at the deposition site according to

$$
C_{\text {ice }} / C_{\text {ice }}^{*}=\left(C_{\text {air }} / C_{\text {air }}^{*}\right)\left(W / W^{*}\right)
$$

where $W$ is the local scavenging ratio. $W$ is defined as $\rho_{\text {air }} C_{\text {ice }} / C_{\text {air }}$ where $\rho_{\text {air }}\left(M / L^{3}\right)$ is the air density. At the same time, the total deposition flux can be approximated with the wet deposition flux $\Phi_{\text {wet }}$, which changes can be calculated from:

$$
\Phi_{\text {wet }} / \Phi_{\text {wet. }}^{*}=\left(C_{\text {air }} / C_{\text {air }}^{*}\right)\left(W / W^{*}\right)\left(P / P^{*}\right) .
$$

If wet deposition is negligible, the concentration in the ice is inversely dependent on precipitation rate, while the total deposition flux (approximated with the dry deposition flux $\Phi_{\mathrm{dry}}$ ) is independent of precipitation rate.

\section{CLIMATE-CHANGE INFLUENGE}

Different climatic stages are characterized by different temperatures and thus significantly different precipitation rates along the transport path. The wet deposition flux of an impurity can be described by

$$
\Phi_{\text {wet }}=\rho_{\text {water }} C_{\text {prec }} P
$$

where $\rho_{\text {water }}\left(M / L^{3}\right)$ is the water density and $C_{\text {prec }}(M / M)$ is the concentration in the precipitation. The mass scavenged can also be calculated by integration of Equation (1). Assuming that the aerosol is well mixed up to the cloud elevation $H$, the integral can be solved, and conservation of mass consequently gives

$$
\rho_{\text {water }} C_{\text {prec }} P=\Psi C_{\text {air }} H .
$$

The average residence time $(\tau=1 / \Psi)$ can thus be related to the precipitation rate as follows:

$$
\tau=\left(\rho_{\text {air }} H\right) /\left(W P \rho_{\text {water }}\right) .
$$

The average residence time is inversely proportional to the precipitation rate which may vary by different degrees along the transport path. The precipitation rates will vary most at high latitudes, and more over the continents than over the oceans. The variations in $H$ and
$W$, neglected in the following estimate of varying residence times, are assumed to be of minor importance. However, variations in the local $W$ may be important for the relation between the concentration in the ice and airborne concentration (Equation (5)). The influence on the residence times from possible changes in chemical transformation processes due to a changed atmospheric-aerosol composition is also neglected in this simple model simulation.

Precipitation rates on Renland were lower by roughly a factor of five (Johnsen and others, 1992a) in stage 2 (the Last Glacial Maximum). A similar decrease in precipitation rates has been found for Camp Century and Dye 3 (Johnsen and Dansgaard, 1992). The latest results from Summit ice cores indicate a smaller reduction in precipitation rates in the interior of Greenland (Dansgaard and others, 1993). Thus, a reduction by a factor of five in stage 2 can be assumed to be at the upper limit for Greenland. If the transport paths were along the same latitude as the Greenland deposition site, a similar reduction in precipitation rates along the entire transport paths can be assumed. Air masses from lower latitudes probably experienced less of a reduction, while air masses travelling along a northerly path, perhaps north of the Laurentide ice sheet (Anderson and others, 1988), possibly experienced an ever larger reduction. In this simulation, the maximum estimate for Greenland is used and extrapolated over the entire transport path. An overall decrease of $P$ to $20 \%$ of present values along the transport path corresponds to a factor-of-five increase of $\tau$. If mean wind speeds were doubled (personal communication from S. Harrison, 1994) at the same time, transit times may have been reduced by a factor of two. This gives an estimated possible variation of the $n / k$ ratio from 1 in the present climate to a minimum of 0.1 in stage 2. The gradual change of $k$ with climate is, in this model simulation, set inversely proportional to the accumulation rate at Renland (which is exponentially related to the $\delta^{18} \mathrm{O}$ record). The gradual change of $n$ is set proportional to the temperature at Renland (which is linearly related to the $\delta^{18} \mathrm{O}$ record $)$. The 19 th century $\left(\delta^{18} \mathrm{O}=-27.4 \%\right.$ o is chosen as the reference state.

\section{MODEL RESULTS}

The magnitude of the variation in $n / k$ is more important the larger the ratio between transit time and residence time in the reference state $\left(t^{*} / \tau^{*}\right.$ ) (Fig. 2 ). The estimated maximum change in $n / k$ (to 0.1 in stage 2) will increase airborne concentrations at Renland in stage 2 by a factor of ten if the $t^{*} / \tau^{*}$ ratio is 2.5. The results of a change in the $n / k$ ratio (to 0.1 in stage 2) for four different $t^{*} / \tau^{*}$ ratios are shown in Figure $3\left(C(0)_{\text {air }} / C(0)_{\text {air }}^{*}\right.$ and $W / W^{*}$ are kept constant). The variation in $n / k$ can be expected to be general for all impurities, while the $t^{*} / \tau^{*}$ ratio is individual for each impurity, depending on the location for each impurity source and the individual average residence time. A high $t^{*} / \tau^{*}$ ratio gives a strongly increasing concentration and an increasing wet deposition flux with a colder climate; a low $t^{*} / \tau^{*}$ ratio gives a 


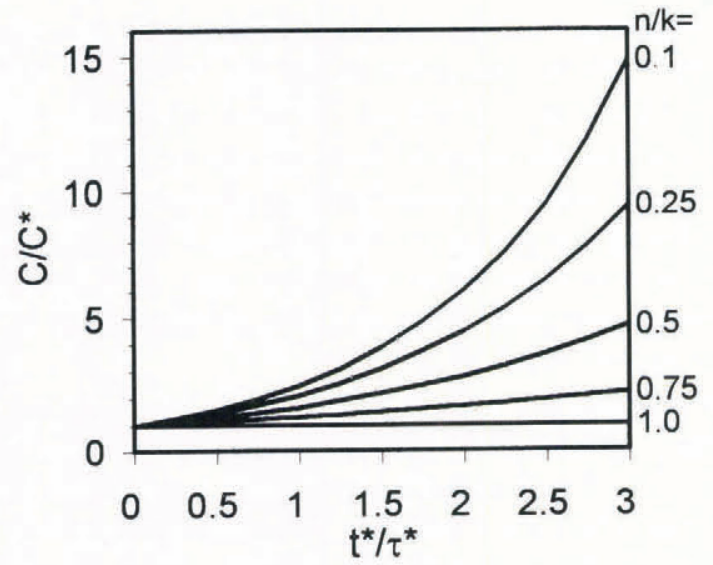

Fig. 2. The relative airborne concentration against the ratio between the transit time and the residence time in the reference state $\left(t^{*} / \tau^{*}\right)$ for different ratios between the relative transit time and the relative residence time $(n \mid k)$.

slightly increasing concentration and a decreasing wet deposition flux, which is due to a decreasing local precipitation rate. Distant sources give rise to high $t^{*} / \tau^{*}$ ratios and local sources to low $t^{*} / \tau^{*}$ ratios. This means that deposition sites far away from the sources will be sensitive to changes in transit times and residence times.

A decrease in airborne concentration at the source with decreasing temperature $\left(C(0)_{\text {air }} / C(0)_{\text {air }}^{*}<1\right)$ or a decrease in the local scavenging ratio at Renland $\left(W / W^{*}<1\right)$ as an effect of less riming (Barrie, 1985) counteracts the effect of a large change in $n / k$. An increase in airborne concentration at the source with decreasing temperature $\left(C(0)_{\text {air }} / C(0)_{\text {air }}^{*}>1\right)$ or an increase in the local scavenging ratio at Renland $\left(W / W^{*}>1\right)$ due to a weak inverse dependency of $W$ on $P$ (Barrie, 1985) adds to the change (i.e. acts in the same direction as a decrease in the $n / k$ ratio). Thus, changes in source emissions or local scavenging ratios cannot be excluded by comparing the results from the model simulation with the observed variations of concentrations and fluxes, since the exact values of $t^{*} / \tau^{*}$ and $n / k$ are unknown. However, any changes in source emissions will be seen as individual changes in the patterns for each impurity, while physical changes in the atmosphere influencing transport and deposition processes (including local scavenging ratios) will change the patterns for all of them systematically.

\section{OBSERVATIONS}

The observed variations in the Renland ice core of concentrations in the ice and total deposition fluxes can be divided into three groups, although the impurities originate from many different sources and source types. Mean concentrations and mean fluxes relative to the 19th-century values against mean $\delta^{18} \mathrm{O}$ values for different climatic stages are shown in Figure 4. The first group, with dust, non-sea-salt (nss) $\mathrm{Ca}^{2+}$ and nss $\mathrm{Mg}^{2+}$, shows strongly increasing concentrations (up to a factor of ten in stage 2) and increasing fluxes with a colder climate. These crustal impurities are found in the coarse-mode aerosol which implies short residence times in the
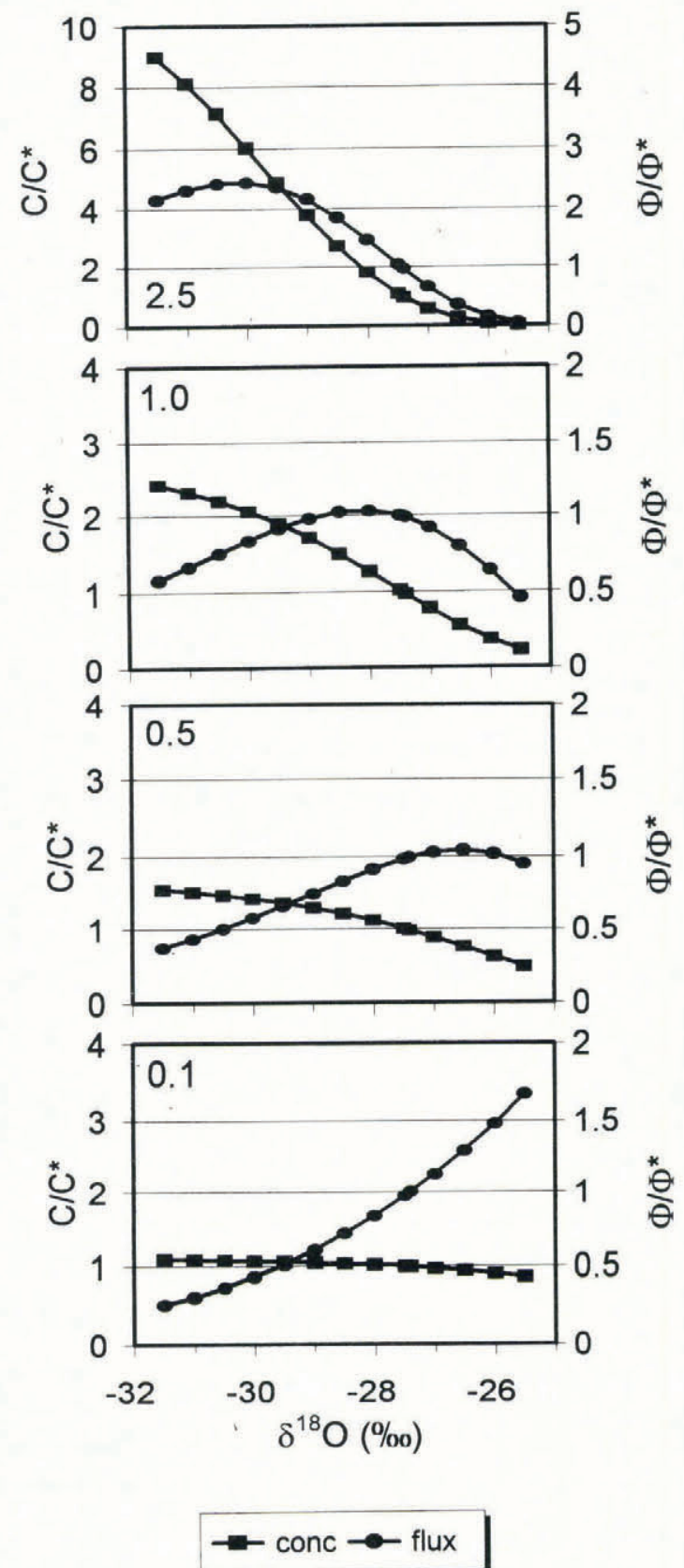

Fig. 3. Model results of the relative concentration in the ice and the relative wet deposition flux for four different $t^{*} / \tau^{*}$ ratios $(2.5,1.0,0.5$ and 0.1$)$ with the same gradual change of the $n / k$ ratio to 0.1 in stage $2\left(\delta^{18} O=\right.$ $-31.3^{\circ} \%$ ). The 19 th century $\left(\delta^{18} \mathrm{O}=-27.4^{\circ} \%\right.$ is the reference state.

atmosphere. The second group, with $\mathrm{Cl}^{-}, \mathrm{Na}^{+}$and nss $\mathrm{SO}_{4}{ }^{2}$, shows moderately increasing concentrations (up to a factor of two in stage 2) and decreasing fluxes. The scattered patterns of nss $\mathrm{K}^{+}$are between these two groups: the concentration increases up to a factor of three but the flux shows a decreasing trend. The flux of dust and nss $\mathrm{K}^{+}$in stage $5 \mathrm{e}$ is exceptionally high. The third group contains impurities with a strong biogenic component. $\mathrm{NO}_{3}{ }^{-}$and $\mathrm{NH}_{4}{ }^{+}$show weak trends of decreasing concentrations with colder climate (although not systematically) and decreasing fluxes. $\mathrm{CH}_{3} \mathrm{SO}_{3}$ (methanesulphonate) shows clearly decreasing concentrations and fluxes with colder climate.

Comparison of the observed characteristic patterns in 

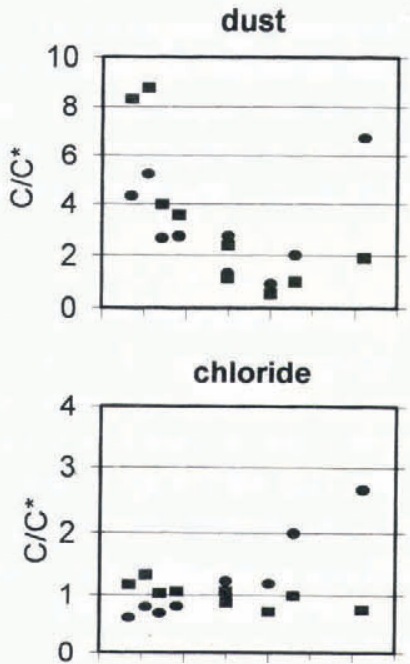

nitrate
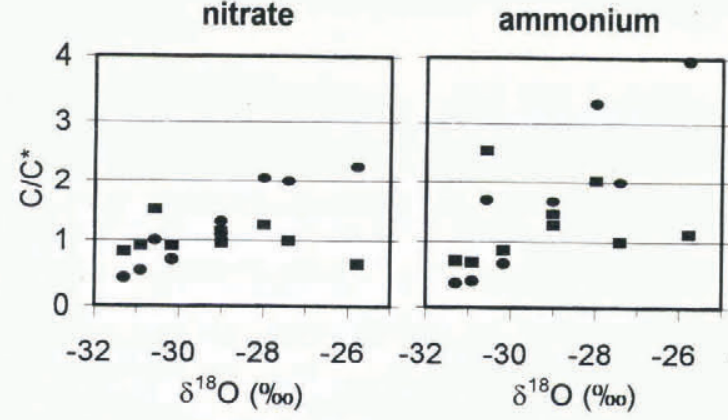

nss calcium

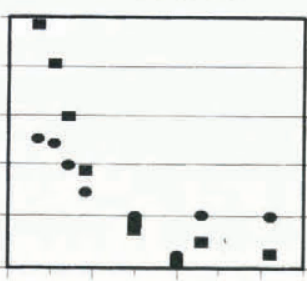

sodium

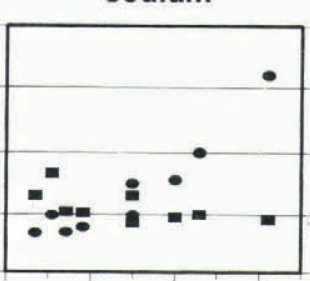

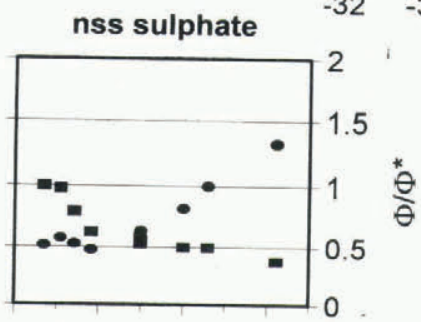

methanesulphonate

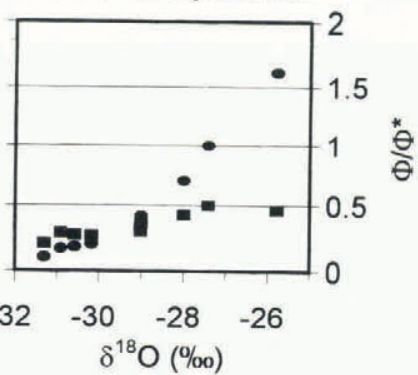

\section{$\stackrel{*}{\ominus}$}

nss potassium
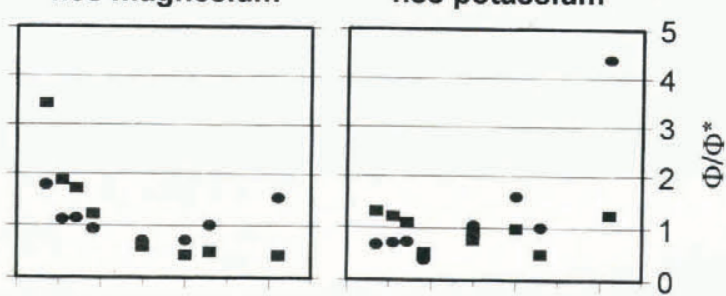

$-30-28-26$

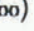

Fig. 4. Observed relative mean concentrations in the ice and relative mean total deposition fluxes for dust and nine ions in the Renland ice core. The 19th century $\left(\delta^{18} \mathrm{O}=-27.4^{\circ} \%\right.$ is the reference state. The other mean values are calculated for the climatic periods: Preboreal $\left(\delta^{18} \mathrm{O}=-28.0 \%\right.$ oo $)$ Tounger Dryas $\left(-30.6^{\circ} \%\right.$ ), Alleröd-Bölling $\left(-29.0^{\circ}\right.$ oo $)$, stage 2 $(-31.3 \%)$, stage $3(-30.2 \%)$, stage $4(-30.9 \%)$, stage $5 a-d(-29.0 \%$ and stage $5 e(-25.8 \%)$, respectively.

the first two groups with the model results (Fig. 3) shows that these patterns can be explained entirely by a likely general change in the $n / k$ ratio. No increase in source emission is necessary, however possible, to explain a tenfold increase in impurity concentration. The difference between the two groups can be explained by different $t^{*} / \tau^{*}$ ratios. If the impurities have similar transit times, shorter residence times for the larger crustal impurities in the first group will give higher $t^{*} / \tau^{*}$ ratios and hence a stronger increase of the concentrations and fluxes with the same general change in the $n / k$ ratio. The patterns of the first group can be reproduced with a $t^{*} / \tau^{*}$ ratio of about 2.5 and the patterns of the second group with a $t^{*} / \tau^{*}$ ratio slightly below 1 , if $n / k$ is changed to 0.1 in stage 2 . The relation between the $t^{*} / \tau^{*}$ ratios for the two groups, $\left(t_{1}^{*} / \tau_{1}^{*}\right) /\left(t_{2}^{*} / \tau_{2}^{*}\right)$, is consistent with the relation between estimated residence times for fine-mode and coarse-mode particles $\left(\tau_{2}^{*} / \tau_{1}^{*}\right)$ in the present-day atmosphere above the boundary layer (Jaenicke, 1988).

However, decreasing concentrations and fluxes with a colder climate imply a decrease in airborne concentration at the source if the impurity is affected by a general change in the $n / k$ ratio. Another possibility is an increase in distance to the influencing source area, but then the source area must be located so much farther away that the transit time increases more than the residence time, i.e. $n / k$ must be above 1 . The concentrations and fluxes of the biogenic impurities in the third group are found to decrease in glacial stages in ice cores from Greenland, but to increase in ice cores from Antarctica Legrand and others, 1988, 1991). This difference may be attributed to shorter distances (which give shorter transit times and hence lower $t^{*} / \tau^{*}$ ratios) from the sources in the Northern Hemisphere to Greenland than from sources in the Southern Hemisphere to Antarctica. Thus, the Antarctic deposition sites may be more sensitive to changes in residence times and transit times. It could also indicate that the distances to influencing source areas in the Northern Hemisphere were extended during glacial stages due to the vast ice sheets over North America and Scandinavia and the larger sea-ice cover in the North Atlantic, but this would also influence other terrestrial and marine sources. The third possibility, of a different response of the biogenic sources in the two hemispheres to climate changes, seems less likely.

\section{IMPLICATIONS FOR THE GLOBAL ATMOSPHERE}

The different possible explanations for the variations seen in ice-core records will have different implications for the total content of impurities in the global atmosphere. If an increased source strength is responsible for enhanced concentrations in the ice sheets, the airborne concentrations of that impurity will be proportionally higher everywhere along the transport path. If enhanced concentrations in the ice sheets are due to changes in 
residence times and transit times, the glacial scenario presented above will mean a more even distribution of all impurities, with decreased airborne concentrations near the sources but increased airborne concentrations far away (e.g. in polar areas). The total content of impurities in the atmosphere will be enhanced in both cases, but the enhancement can be significantly different as is shown below.

Integration of Equation (2) over the transport path will give the total content, $M(M)$, of an impurity in the atmosphere. The relative total content can thus be described by

$$
M / M^{*} \propto C(0)_{\text {air }} / C(0)_{\text {air }}^{*} k / n .
$$

As a consequence, the total content of sulphate in the atmosphere was increased by a factor of ten in stage 2 if the observed two-fold increase of sulphate in the ice at Renland was due to a change of the residence time and transit time corresponding to $n / k=0.1$, but increased only by a factor of two if the same observed two-fold increase was due to a two-fold increase in source strength. In the case of calcium, the two possibilities, a change of the residence time and transit time corresponding to $n / k=0.1$ or a ten-fold increase in source strength, will both have given a ten times higher load of calcium in the atmosphere.

Thus, changes in the hydrological cycle and the general circulation can have a large impact on the total content of impurities in the atmosphere and hence on the radiative properties of the atmosphere. This implies that a climate-forcing mechanism may be found in the dynamics of the atmosphere by the course of events: lower temperatures $\rightarrow$ lower precipitation rates $\rightarrow$ less atmospheric cleansing of impurities $\rightarrow$ longer atmospheric residence times $\rightarrow$ higher impurity concentrations in the atmosphere $\rightarrow$ more reflected solar flux $\rightarrow$ lower temperatures. The magnitude of the influence on the climate can be deduced from a comparison with the present-day conditions. The change of reflected solar flux due to the direct back-scattering effect of anthropogenic sulphate aerosol particles (approximately three times the natural background) averaged over the Northern Hemisphere is calculated to be about $-1 \mathrm{~W} \mathrm{~m}^{-2}$ (Charlson and others, 1991). This is comparable, but opposite in sign, to the current greenhouse forcing by increased $\mathrm{CO}_{2}$ to date. It is not yet possible to estimate the aerosol particles' indirect effect on cloud albedo arising from their role as cloud condensation nuclei.

\section{CONGLUSIONS}

This simple model simulation shows that for many of the soluble and insoluble impurities measured in polar ice cores, the changes in the physical conditions of the atmosphere are sufficient in themselves to account for all the observed variations in the concentrations. This means that interpretations of changes in source emissions have to be made with caution from records of deposition. It also shows how important it is to understand the reasons behind the observed variations in impurity concentrations in ice cores before extrapolating the results to a global scale. The total content of impurities in the glacial atmosphere was higher if changes in atmospheric cleansing rather than in source emission were responsible for the variations observed in polar ice cores. The first alternative leads to a five times higher total content of sulphate in the glacial atmosphere than the second alternative. Thus, variations in the atmospheric cleansing can strongly affect the radiative properties of the atmosphere. This implies that a climate-forcing mechanism is to be found in the dynamics of the atmosphere, with an effect comparable in magnitude, but opposite in sign, to the present-day anthropogenic greenhouse forcing. It is essential to attain a better knowledge of the atmospheric conditions during glacial stages to take full advantage of the ice-core records.

\section{REFERENCES}

Anderson, P. M. and 32 others. 1988. Climatic changes of the last 18,000 years: observations and model simulations, Science, 241 (4869), $1043-1052$.

Barrie, L. A. 1985. Atmospheric particles: their physical and chemical characteristics, and deposition processes relevant to the chemical composition of glaciers. Ann. Glaciol., 7, 100-108.

Charlson, R. J., J. Langner, H. Rodhe, C. B. Leovy and S. G. Warren. 1991. Perturbation of the Northern Hemisphere radiative balance by backscattering from anthropogenic sulfate aerosols. Tellus, 43A, 152 163.

Dansgaard, W. and 10 others. 1993. Evidence for general instability of past climate from a 250-kyr ice-core record. Nature, 364(6434), 218-220.

Dibb. J. E., J.-L. Jaffrezo and M. Legrand. 1992. Initial findings of recent investigations of air-snow relationships in the Summit region of the Greenland ice sheet. J. Atmos. Chem., 14(1-4), 167-180.

Greenland Ice-core Project (GRIP) Members. 1993. Climate instability during the last interglacial period recorded in the GRIP ice core. Nature, 364 6434), 203-207.

Grootes, P.M., M. Stuiver, J. W. C. White, S. Johnsen and J. Jouzel, 1993. Comparison of oxygen isotope records from the GISP2 and GRIP Greenland ice cores. Nature, 366 (6455), 552-554.

Hansson, M.E. 1994. The Renland ice core: a Northern Hemisphere record of aerosol composition over 120,000 years. Tellus., 46B, $390-418$.

Jaenicke, R. 1988. Aerosol physics and chemistry. In Fischer, G., ed. Meteorology. Vol. 4. Berlin, Springer, 391-457.

Jaffrezo, J.-L. and C. I. Davidson. 1993. The Dye 3 Gas and Acrosol Sampling Program (DGASP): an overview. Atmos. Environ., 27A 17 18), 2703-2707.

Johnsen, S.J. and W. Dansgaard. 1992. On flow model dating of stable isotope records from Greenland ice cores. In Bard, E. and W.S. Broecker, eds. The last deglaciation: absolute and radiocarbon chronologies. Berlin, Springer-Verlag, 13-24.

Johnsen, S. J. and 7 others. 1992a. A “deep" ice core from East Greenland. Meddr. Grenl. Geoscience 29.

Johnsen, S.J. and 9 others. 1992b. Irregular glacial interstadials recorded in a new Greenland ice core. Nature, 359 6393), 311-313.

Joussaume, S. 1993. Paleoclimatic tracers: an investigation using an atmospheric general circulation model under ice age conditions. 1. Desert dust. f. Geophys. Res., 98(D2), 2767-2805.

Legrand, M. R., C. Lorius, N. I. Barkov and V. N. Petrov. 1988. Vostok (Antarctica) ice core: atmospheric chemistry changes over the last climatic cycle (160,000 years). Atmos. Environ., 22 2), 317-331.

Legrand, M.. C. Feniet-Saigne, E.S. Saltzman, C. Germain, N. I. Barkov and V.N. Petrov. 1991. Ice-core record of oceanic emissions of dimethylsulphide during the last climatic cycle. Nature, $\mathbf{3 5 0} 6314$ ), $144-146$.

Mayewski, P. A. and 7 others. 1993. The atmosphere during the Younger Dryas. Science, 261(5118), 195-197.

Staffelbach, T., B. Stauffer and H. Oeschger. 1988. A detailed analysis of the rapid changes in ice-core parameters during the last ice age. Ann. Glaciol., 10, 167-170. 